\title{
What Impact does an Adult Substance User Have on Mothers, and How do They Make Sense of Their Experience?
}

\author{
Ingela Clare Jackson \\ Department of Lifelong Learning, University of East Anglia, Norwich, Norfolk, UK
}

Copyright $(2018$ by authors, all rights reserved. Authors agree that this article remains permanently open access under the terms of the Creative Commons Attribution License 4.0 International License

\begin{abstract}
Previous research has focused on the impact of substance use on the whole family system, and whether certain family dynamics are common in families with substance use in them. This research, conducted in the UK, explores the specific experience of being a mother of a substance user and their phenomenological experience from the perspective of mothering metanarratives in western cultures today. The findings were complex due to the amount of data, but the theme of loss ran through all of the impacts, as well as being a major part of how the participants made sense of their experience. Loss was therefore the focus for studying the impact on the participants. The findings showed the complexity of mothering for this group of women and how their experience is largely misunderstood and unsupported in our society, where mother blaming is culturally acceptable.
\end{abstract}

Keywords Substance Use, Families, Mothers, Mothering Metanarratives, Mother Blaming

\section{Introduction}

Until recently UK governmental policies have been unsupportive of a family's caring role for the user, and not until the Coalition Government's 2010 Drug Strategy were the specific needs of family members quoted within a national policy document in England. Despite the huge impact on the lives of relatives their needs have historically been largely ignored, and there is an unspoken assumption in Treatment Services that families are 'part of the problem' Orford [1]. Yet these families live with the daily trauma of seeing someone they love slowly kill him or herself and experience domestic violence, verbal and emotional abuse, constant worry, shame, fear of police and social exclusion, isolation, anger, helplessness, powerlessness (Orford et al, [2]); the list goes on and has many parallels with the experience of users.

In western society mothering is undervalued (Phoenix [3]) and that, coupled with the mothering bond (McMahon [4]) seems to add an extra layer of complexity and pain to the experience of seeing someone you love misuse substances. For the purposes of this research, a substance user is defined as someone whose using significantly impairs their ability to live functionally.

Historically research into families with substance users has focused on the family system as a predictor of substance use (Hopper et al. [5]; Spooner \& Hill [6]; Myles \& Willner [7]). Specific parental behaviours were associated with adolescent substance use (Barnes, [8]; Needle et al, [9]) leading to a culture of blame and stigmatization (Jackson \& Mannix, [10]: Caplan \& Hall-McCorquodale, [11]). Only more recently has research begun to focus on the support families need in their caring role (Toumbourou \& Bamberg, [12]; Yuen \& Toumbourou, [13]).

Despite this shift there is little research into the phenomenological experience of mothering an adult user (Orford et al, [14]). The individual impact on each family member is unheard, nor is there an understanding of the different coping behaviours a mother might have, compared to a father or sibling for example (Orford et al, [2]). Questions such as 'am I a "good enough" mother?' (Winnicott: [15]), 'did I fail as a mother?' 'what could I have done differently?' 'where did I go wrong?' 'what kind of person does this make me?' are not acceptable mothering narratives in Western society (Swigart, [16]), leaving these women effectively silenced.

\section{Materials and Methods}

This was a small-scale qualitative research where five participants were interviewed about their experience using semi-structured interview questions. Interpretive Phenomenological Analysis (IPA) (Smith et. al., [17]) was 
used as the framework to allow the descriptive, linguistic and conceptual elements of the participants' narrative to be analyzed in detail, from which superordinate themes then emerged. Aspects of narrative research and Gendlin's [18] Critical Thinking at the Edge were also used to investigate the "boundaries of the phenomenon" (Todres, [19]: 57).

The participants were all white, educated, middle-class women with European ethnicity so my findings are culturally specific and in that sense limited. Participants were aged between mid-50 and 75 and their adult children (three daughters and two sons) were aged between late 20's and mid 40's. All have used alcohol and/or drugs upwards of ten years. Alcohol was the primary drug of choice for two, one used ketamine, one used heroin, and one used multiple drugs. Three out of the five users were still dependent on their mother and family unit both emotionally and financially, but only one was living with his birth family.

\subsection{Data Collection}

Semi-structured interviews lasting between one and two hours were recorded and used to obtain participants' detailed accounts of their experiences. The interview questions were open-ended and intended to enable the participants to explore their experience in a way most meaningful for them.

\subsection{Data Analysis}

The analysis of the data followed the process outlined in Smith et al. [17]. The transcripts were read in close detail and coded according to descriptive, linguistic and conceptual themes. These formed the subordinate themes, which were then interpreted to form the superordinate themes for each transcript.

Cross analysis was then made between the transcripts to identify an interpretation of all the transcripts from the perspective of metanarratives about mothering in western cultures. The aim was to examine how the participants make sense of their experience from the perspective of what they have introjected from the metanarratives.

\subsection{Limitations}

A shared consciousness between the participants and researcher was the 'historical consciousness' of our community and tradition, and its inherent assumptions of what being a mother in our Western culture means. All our children were born at a time (1970's and 80's) when mothers still largely stayed at home or worked part-time, and the notion of female equality was just coming into law (for example the Equal Pay Act of 1970). Being a mother was still a central identity for women (Swigart [16]). The data of the research is therefore located in a particular time and place, with the researcher as the specific audience, and was then interpreted at a later time and in a particular way (McLeod [20]) for research purposes.

\section{Results}

There were several superordinate themes around which the narratives clustered. These are set out in figure 1 under the metanarratives (discussed below), which frame the sense making of the participants, showing how their sense making in turn informs their behaviour.

\begin{tabular}{|c|c|c|c|c|}
\hline Superordinate Theme & $\begin{array}{l}\text { It is the mother's } \\
\text { responsibility to produce a } \\
\text { well-adjusted child }\end{array}$ & $\begin{array}{c}\text { Mothers should } \\
\text { sacrifice themselves } \\
\text { for their child }\end{array}$ & $\begin{array}{l}\text { Mothers cannot have } \\
\text { ambivalent or negative } \\
\text { feelings about their child }\end{array}$ & \begin{tabular}{|c|}
$\begin{array}{l}\text { It is the mother's } \\
\text { responsibility to keep her } \\
\text { child from harm }\end{array}$ \\
\end{tabular} \\
\hline Responsibility & all & all & $\mathrm{P}, \mathrm{D}$, & all \\
\hline Loss & all & all & all & all \\
\hline Financial impact & $\mathrm{P}, \mathrm{T}$ & $\mathrm{T}, \mathrm{P}, \mathrm{D}$ & $\mathrm{P}, \mathrm{T}, \mathrm{D}$ & all \\
\hline $\begin{array}{l}\text { Mothering and questioning of } \\
\text { self }\end{array}$ & $\mathrm{V}, \mathrm{D}, \mathrm{M}$ & all & $\mathrm{V}, \mathrm{P}, \mathrm{M}, \mathrm{D}$ & all \\
\hline Powerlessness & all & all & all & all \\
\hline Emotional impact & $\mathrm{V}, \mathrm{D}, \mathrm{M}$ & all & all & all \\
\hline Time & $\mathrm{V}, \mathrm{D}, \mathrm{P}$ & $\mathrm{V}, \mathrm{P}, \mathrm{D}, \mathrm{M}$ & all & all \\
\hline Rejection & $\mathrm{V}$ & all & all & $\mathrm{V}, \mathrm{P}, \mathrm{M}$ \\
\hline Lies and lack of trust & $\mathrm{V}, \mathrm{P}, \mathrm{T}, \mathrm{M}$ & $\mathrm{V}, \mathrm{P}, \mathrm{T}, \mathrm{M}$ & all & all \\
\hline Addiction and rehab & $\mathrm{D}, \mathrm{T}$, & all & $\mathrm{D}, \mathrm{T}, \mathrm{V}$ & $\mathrm{T}, \mathrm{D}, \mathrm{V}$ \\
\hline Family dynamics & all & all & all & all \\
\hline Trauma & all & all & all & all \\
\hline Mental illness & $\mathrm{D}, \mathrm{M}$ & $\mathrm{D}$ & all & $\mathrm{D}, \mathrm{V}$ \\
\hline Death & all & $\mathrm{D}, \mathrm{V}, \mathrm{P}$ & all & $\mathrm{D}, \mathrm{V}, \mathrm{P}$, \\
\hline
\end{tabular}

$\mathrm{V}=$ Veronica, $\mathrm{P}=$ Penelope, $\mathrm{T}=$ Teresa, $\mathrm{D}=$ Debbie, $\mathrm{M}$ = Maureen.

Figure 1. Mothering metanarratives in relation to the impact of having a substance using adult child on mothers 
The left hand column in Figure 1 demonstrates the significant impact on the participants' personal lives; however the superordinate theme that runs through all is loss, which is therefore the focus for the discussion about impact.

\subsection{Impact}

All the participants expressed a loss of connectedness and relational attachment with their adult child. Zelizer [21] argues mothers focus on their connectedness with their children because they are sacred-like objects in western cultures. Losing one's child is therefore losing the mother's relational self and the role of being a mother, which provides their sense of connectedness (Lofland, [22]). In the case of Veronica and Debbie the personality change in their daughters is akin to psychosocial death (Doka, [23]) because their personality changed so significantly they are no longer recognizable as the person they once were.

The participants have lost the son or daughter they once had, but also the person their child might have become, whilst simultaneously struggling with the person they are. This prolonged mourning is unacknowledged or supported by friends, family or support services. So added to the loss of the mother/child relational connectedness is the loss of social bonding as well. This is demonstrated by the isolation the participants described and their marginalized feelings, because the focus is on the substance user.

This protracted mourning is made worse because they cannot exit the stages of grief as described by Worden [24]. Their continuing caring role prevents them from coming to terms with their feelings in order to move on with their lives, because the ongoing relationship adds more painful experiences causing new stress, shame, guilt, anger and helplessness.

Another complex loss is the participants' underlying sense that substance use was chosen by their child. They struggled with accepting the substance use issues might be forever, and their stories are hallmarked by endurance and adaptation to their situations. Accepting their adult child might never be free of substances is almost impossible for these women to comprehend. This can lead to a deeply guilt-provoking desire for the user to die, expressed by two participants. The pain is of no end or closure. Even if the user recovers there is still the constant fear of relapse, taking away any sense of security.

Another aspect of loss the participants express is the 'narcissistic blow' women feel when they become irrelevant to their adult child after so many years of giving their love (Swigart [16]). For some mothers it is hard to relearn how to satisfy and fulfill their own needs after the self-sacrifice and self-denial of looking after small children (which is rewarded by the child's powerful love and need). They have lost the part of themselves that is separate from their child and need to be needed in order to feel important and worthwhile, and to avoid feelings of abandonment, loneliness or emptiness (Swigart [16]). All the participants have lost the next stage of their life, retirement or grand-parenting, because they have become surrogate parents for grandchildren, or their lives are still dominated by their active caring role.

Their complexity of relationships is shown in the 'stickiness' of dependence versus independence, sometimes called codependence (Beattie, [25]).

\subsection{How do They Make Sense of Their Experiences?}

"Becoming a mother is not simply an expression of gender identity acquired in childhood; it is also an experience that produces and reproduces in women a gendered sense of adult self. That is, it reproduces ways of acting, thinking, and feeling that are conventionally associated with being female" (McMahon, [4]: 191).

McMahon's argument that women's thinking, behaviour and feelings are socially organized, points to the restrictive nature of the metanarratives in western cultures available to women. Historically romantic love has been a central organizing emblem for individual identity, moral choice and social commitment. The medieval courtly tradition of love was an expression of one's morality and self-discipline; bourgeois love is about fulfillment of self, and by the $19^{\text {th }}$ century, falling in love and marrying was a woman's rite of passage into adulthood (Swidler, [26]). Swidler argues when romantic love lost its social place in forming women's identity, maternal love replaced it. Mothering has become a moral test of one's worth and allows women to achieve a feminine identity as a loving, caring, responsible person (McMahon, [4]).

The assumption that a woman's mothering reflects her character and identity makes it problematic for mothers to honestly admit the complexity of their experience and feelings about mothering. The limiting nature of mothering metanarratives means the participants couch their feelings in terms of struggle, justifications of their actions, or denial.

First metanarrative: it is the mother's responsibility to produce a well-adjusted adult.

Essentially this discourse implies the moral welfare of the next generation is the responsibility of mothers (Phoenix et al, [3]). Any social problems are the result of faulty mothering, which induces many layers of guilt. The participants questioned certain childhood incidents in the belief they misunderstood earlier behaviours of their children that indicated how things turned out. They assume if they had acted on those earlier signs they might have been able to lessen, delay or even prevent the substance use.

All the participants skirt round the difficult question of whether their mothering caused permanent damage to their child. The metanarrative is a lens that seemingly reflects back their own deficiencies as mothers.

Second metanarrative; mothers should sacrifice themselves for their child.

The roles of mothering and the mother's character as a 
person have become merged in western cultures (McMahon, [4]; Smith \& Estefan, [27]; Swigart, [16). McMahon argues if you are a mother you must be attuned to the needs of your child, be self-sacrificial, loving, patient, and so on.

When the participants maintain they have done everything possible to help their children, and justify why they acted the way they did, they are expressing this metanarrative.

Part of this metanarrative is underpinned by the Christian belief that sacrifice is redemptive, which is part of western culture. The impasse is the participants have sacrificed a huge amount but not changed the situation. When they look at the damage to themselves, they question whether it was worth it.

These painful thoughts are minimized because they do not sit easily with the metanarrative of being loving and self-sacrificial. Instead they couch it in terms of loss; loss of their own life and what they have been unable to do because of their caring role, for example form new partnerships or relationships. They struggle to nourish themselves and find a sense of self that is separate from their caring role.

Third metanarrative; mothers cannot have ambivalent or negative feelings towards their child.

This metanarrative has aspects of the second one; 'good' mothers interact appropriately with their children, including having acceptable feelings towards them. However Swigart [16] comments our children's ambivalence towards us induces ambivalence in us towards them, unless we are saints (which is part of the 'mommy myth' (Douglas et al, [28]). It is not acceptable in our society for a mother to say she dislikes her child. Nor can mothers say they want to walk away, or give up on their child. The participants all feel guilty about their negative feelings so they frame their narratives about their mothering in socially acceptable ways. Their key narratives become 'I didn't have a choice', 'I have to sort it', 'I am a victim', 'I am overwhelmed and cannot cope', 'I tried my best but failed' and 'my love must be able to sort this'. They are left trapped in Karpman's drama triangle (victim/persecutor/rescuer) (Stewart \& Joines, [29]) rather than connecting authentically with their experiencing.

They struggle with huge guilt at the gap between their negative feelings and self-concept. For example Penelope expressed her ambivalence saying "Louise is very wonderful" (from her 'good mother' self-concept) but elsewhere says she wants to walk away and have nothing more to do with her. Debbie felt guilty that in the past she sometimes preferred her daughter to be drunk in the evenings so that she could sleep herself. Resentment, another inadmissible feeling, lurks beneath the surface of all their narratives. Not being able to express their negative feelings means incongruence between who they are and who they feel they should be which in turn leads to conflicted identity. Their inability to vocalize their negative feelings comes out in the physical illnesses they mention, and how they have aged prematurely through stress caused by the strain and lack of support.

Fourth metanarrative; it is a mother's responsibility to keep her child from harm.

This metanarrative expresses mothers' moral obligation and duty is to keep their child from harm. The participants have been unable to do this, so no matter how good their mothering was, they struggle with feelings of failure because of the outcome.

Gilligan [30] hypothesizes men's morality is governed by principles of justice and rights and they form their identity through separation, whereas women define themselves through relationship with others, so their morality is governed by caring and responsibility. McMahon [4] similarly argues motherhood is a moral transformation for many women because they become less selfish and more caring; it exposes their good and bad strengths and is a 'test' of their moral fibre.

The participants' narratives bring out their unconscious struggle to try to come to terms with the question "am I a good mother? And if my experience is proof that I am not, then how do I come to terms with being a failed mother?" Their inability to let go of their adult child shows they are still trying to 'fix it' and prove their good mothering.

The big implicit question they all ask is 'who am I as a person if I failed as a mother?' The answer is all the years of love and attention they have given to their child are judged by society as a waste, which is existentially intolerable. Their personhood is threatened because the role of mothering is inextricably bound up with one's character, so they cannot give up.

Mothering metanarratives define these women as caring, nurturing and relational but their adult children's substance use has pushed those social constructs to the limits. Their unconscious efforts to align themselves and fulfill the metanarratives create a tension and disruption between their experience of being a mother and how others perceive them. This tension makes too high a demand on their sense of self, meaning they feel a failure, which they cannot accept; the incongruence between their experiencing and self-concept is too great. These women are the story because they have lost their own autonomy in their struggle with their adult child's substance use. Loss encapsulates the other superordinate themes but is also central to their sense making; it is the acceptable face of their unacceptable feelings and is the story that is 'allowed' whereas their complex experiencing is not.

\section{Discussion}

\subsection{A Short Review on the Socially Constructed Nature of Mothering}

In order to put the research into perspective, research 
into metanarratives of the experience of mothering was examined. Historically families lived together multi-generationally, so childrearing was in an extended family context. The change to the nuclear family in the $20^{\text {th }}$ century meant childrearing became the exclusive sphere of mothers because men were away from the home doing paid work, leaving women to do the full-time childcare and home-making (Smith \& Estefan, [27]). Socially and culturally, this placed women in a male dominated gender system (Chodorow, [32]; Phoenix \& Woollett, [3]).

In the $20^{\text {th }}$ century mothering became more isolated (McMahon, [4]) and mothers were implicated when children had psychiatric disorders (Freud, [33). Mothering became the subject of 'experts' who were usually men and doctors writing childcare manuals (Phoenix et al, [3]), and psychological theories such as Winnicot's concept of the "good enough" mother ([15]: 145), and Bowlby's [34] attachment theories were developed. Billings [35] argues these psychological child-rearing theories put the blame for psychopathology on mothers. The experts were often prescriptive and emphasized the mother's responsibility to bring up a well-balanced child, as well as recommending what a 'normal family' should look like (Parsons \& Bale, [36]).

Motherhood is therefore socially constructed as valuable and important, but as a role with no economic weight, it is simultaneously undervalued (Phoenix et al, [3]). Phoenix argues motherhood is a positive identity for women, marking their transition into womanhood and confirming their identity as a woman. But as discussed, the role of mothering became merged with the characteristics of a 'good' mother, and synonymous with female identity (McMahon, [4]; Smith \& Estefan, [27]; Swigart, [16]).

This narrow definition of mothering means many women lose their sense of self and neglect their own needs (McGoldrick, Anderson, \& Walsh, [37]). It also ignores whole groups of women who are pathologized by society as 'bad' mothers, for example unmarried mothers, mothers under 18 or over 40 , mothers on benefits, and so on (Jackson \& Mannix, [38]). As diversity increases in the $21^{\text {st }}$ century, more groups of mothers are being pathologized, for example lesbian mothers (Wright \& Leahey, [39]).

Similarly, the introjected 'good mother' leaves no room for mothers to express ambivalence about their child (Swigart, [16]; Smith \& Estefan, [27]) because society only views mothers as good or bad; to have negative feelings about your child relegates mothers to the 'wicked mother' status of fairy stories such as Snow White or Cinderella (Chaplin, [40]). This silences many women as they have no 'self-narrative story' to tell if their child has not turned out ok (Smith \& Estefan, [27]) except as bad, or failed mothers whose love has been inadequate. Maushart [41] calls this silence the "mask" of mothering because the complexity of parenting children experiencing difficulties is unspoken. The tension between societal expectations of the 'good' mother and the 'mask' of motherhood means many women's experiences are suppressed (Smith \& Estefan,
[27]). There is a dearth of research that gives insight into the experiences of mothers whose story is one of failed love because of substance use; it is the shadow side of the story-myth that 'love conquers all' (Smith \& Estefan, [27]).

From this study's perspective, the impact of societal belief in the 'good mother' induces guilt in mothers where problems such as antisocial behaviour like substance use develop (Swigart, [16]; Smith \& Estefan, [27]). Mothers are blamed for the health and behaviour of their children, even when they are grown up, in a way that fathers are not (Jackson \& Mannix, [38]; Swigart, [16]). Feminists argue it is easier to blame mothers for family problems or maladjusted children (even when they are adults) and ignore the difficult circumstances in which they are mothering (Jackson \& Mannix, [38]), rather than change government policies, or look at how society and business structures are unsupportive of women's mothering (Phoenix et al, [3]). This culturally accepted 'mother-blaming' manifests itself within families, friendships, and society in general.

The mother-blaming culture amongst health professionals reflects this cultural 'norm' of attributing blame to mothers (Jackson \& Mannix, [38]: Caplan \& Hall-McCorquodale, [11). For example, an analysis of nine clinical journals published in 1970, 1976 and 1982 found 72 psychopathologies attributed to mothers, including arson, fetishism, frigidity, incest, incontinence, schizophrenia, sibling jealousy, transexualism, tantrums and ulcerative colitis. None had positive only descriptions of mothers' relationships with their children and the father was never considered as a potential contributor (Caplan, Hall-McCorquodale [11]).

Jackson et al [10] found women health care professionals were just as likely as their male colleagues to blame mothers, and mothers are the recipients of much humiliation, misunderstanding and discrimination from health professionals (Orford, [1]). Women internalise that sense of blame, guilt and inadequacy, even for things they could not possibly be responsible for and are beyond their control. When families are affected by substance use they are stigmatized by this supposed moral failure of the mother, and the implication she failed to prevent the problem (Jackson \& Mannix, [38]). The result is women are reluctant to access potential support (Mannelli, [42). This climate of blame is not helpful or conducive to healing (Jackson, Usher, O’Brien, [43]; Smith \& Estefan, [27]).

\subsection{Research on Family Systems as Predictors of Substance Use}

Until recently the mother-blaming culture was a major premise in substance use research (Smith \& Estefan, [27]), and presumed dysfunctions in the family system can predict adolescent substance use (Anderson et al, [44]; Barnes, [45]; Volk et al, [46]: McCubbin et al, [47]). A large body of research links adolescent drug abuse with family risk factors (Hopper et al. [48]; Myles \& Willner 
[7]).

\section{Indicative Risk Factors}

Some of the research is contradictory about whether it describes family system characteristics resulting from the presence of substance use, or the causal factors. The underlying assumption is the family system is part of the problem, which encourages the blame culture amongst health professionals (Orford, [49]). However most of the research amalgamated several kinds of family relationships, such as siblings, partners and parents in order to make generic conclusions (and some were the substance users perspective on their parents), rather than examining the diverse impact on different family members. The individual and personal reality of living with someone who is abusing substances is ignored (Jackson et al, [46]).

\subsection{Research Findings on the Impact of Substance Use on Family Members}

Current research is moving towards a holistic understanding of the family (Baldwin et al, [50]; Toumbourou \& Bamberg, [12]; Yuen \& Toumbourou, [13]) and towards understanding the 'lived experience' of families with a substance user (Usher, et al [51]). However, most look at families with adolescents, not adult children, so the long-term effects of living with the issue are not clear (Copello et al, [66]). This research recognizes the family burden of caring for a substance user.

\section{Health}

Copello et al's [66] research, based upon the collective findings of a number of studies conducted in several countries during the past 20 years, shows families of substance users use health care services more than the general population (Svenson et al, [52]), and demonstrates the heavy toll of living with a substance user. Copello et al [66] found families suffer from physical symptoms such as tiredness from poor sleep patterns and lying awake worrying, skin conditions such as eczema, and headaches such as migraines. They also listed sickness; anaemia; neuralgia; back pain; 'pains'; hypertension; asthma; hair loss; change in bowel movements; gall bladder trouble; shortness of breath; palpitations; diarrhoea; 'minor ailments' and itching. Eating dysfunctionally is common: over eating, loss of appetite, and being unable to eat. The person's weight therefore yo-yos up or down which, from personal experience of the client group, negatively impacts their self-esteem.

Psychological effects were anxiety or panic attacks, trauma symptoms, being unable to concentrate, depression, feeling suicidal, generally feeling unwell, feeling weak and fragile, and feeling they had aged more quickly from the stress (Copello et al, [66]; Wegner et al, [53]). In some cases the strain meant family members turned to substances themselves, such as smoking, drinking, taking antidepressants, or other prescribed or illegal drugs (Howells \& Orford, [54]; Orford et al, [47]; Orford et al, [2]).

\section{Emotional}

Families describe the difficulty in accepting the lies and deceit of the user and how they live in denial (Jackson et al, [10]). Other common feelings reported are disempowerment, worry, anxiety, stress, feeling isolated, guilt, shame, anger, resentment, poor self-esteem, depression, confusion over what to do, feeling emotionally manipulated, threatened, fearful and exhausted (Orford et al, [2]). From my experience with this client group, they are on a constant rollercoaster of hope and despair, dependent emotionally on the user's behaviour. Wegner et al [53] reports the strain of the constant lies, false hope and emotional manipulation, so mothers end up doubting themselves and even become psychiatrically ill because of their desperation and powerlessness.

\section{Grief and Loss}

Research findings such as Usher et al [51] and Orford et al [2] report the loss families feel because of the change in the user. They are grieving for the person they have lost (Usher et al, [51]). This "disenfranchised grief" (Doka, [23]) is not socially recognized or openly acknowledged so it cannot be publically mourned. In the case of families of users, they have lost the person they love to the substance; the users are unrecognizable from the person they were, akin to the personality change in a person suffering from Alzheimer's (Suddow, [55], Kalish, [56]). But because they are still alive, the family loss and grief is unacknowledged and there is no support from socially recognized mourning or grief rituals such as a funeral. The lack of formalized mourning stops the re-bonding and stabilization process for the families that public mourning affords, and isolates them instead (Doka, [23]). An added burden is substance users are not valued in society, which further devalues and invalidates the family's grief (Chapman, [57]).

\section{Shame and Guilt}

Shame effectively silences families, for example when the substance user is involved with the police, or neighbours witness their antisocial behaviour. This guilt by association isolates family members (Jackson et al, [43]).

As discussed, mothers internalize the cultural assumption that addiction is the result of bad parenting, despite knowing they are loving and caring parents (Jackson et al, [43]). This sense of culpability is underlined by the lack of societal support; they fear being stigmatized, so often do not reveal the extent of the problem. If the extended family is aware of the issue, they may ignore or deny the substance use because of their own fear of being stigmatized (Mannelli, [42]). 


\section{Social}

Fear of stigmatization socially isolates families with a user. Families hide their experiences because seeking help is seen as a family betrayal and lacking loyalty to the family unit (Laslett et al, [58]). Instead they adjust family roles and their ways of relating to minimize the impact (Steinglass et al, [59]). They do not invite other people into their homes for fear of verbal or physical abuse or other antisocial behaviour (Jackson et al, [43]). They do not socialize outside the family home either; the participants reported difficulty going out because they worried about what was happening at home in their absence. They struggle to talk about their children with friends because of unfair comparisons, and hearing about the success of friends' children underlines their own sense of loss and failure. They are too preoccupied with the substance user to do 'small talk' and if they discuss what they are really experiencing, they worry about over-burdening their listener, or being judged.

\section{Domestic Violence}

Research, for example Velleman \& Orford [60] and Barber \& Crisp [61], has shown a significant amount of domestic violence and verbal and emotional abuse towards partners and children is caused by alcohol consumption. This abuse includes child neglect (Jackson et al, [43]). As discussed, families are reluctant to seek support from the police for fear of stigmatization and in my experience only call for help when the violence has escalated to intolerable levels. They feel calling the police proves they are 'bad' parents, and it will be their fault if the substance user gets a criminal record.

Wegner et al [53] found mothers felt forced to allow domestic violence and theft in their homes because they could not monitor and protect their children from the consequences of such behaviour outside the home. This highlights the struggles of these parents and their isolation (Pearson [62]; Jackson \& Mannix [38]: Jackson et al, [43]).

\section{Financial}

Mannelli's [42] study in the USA and Wegner et al's [53] in South Africa found substance users affect other family members' ability to work, and especially mothers because they are the primary caregivers. The mother adjusts her routines to the substance user's lifestyle, hampering her ability to work, and many cannot work because of the worry and strain of home life and/or resulting physical illness (Copello et al, [66]). Mothers are willing to sacrificially use all their finances to fund rehab for the user (Wegner et al, [53]) and the family income is used indirectly to support the users' drug habit. From my experience of the client group money was constantly spent on replacing lost items such as mobile phones, or pawned items like electrical equipment. Families also suffer financial loss through valuables such as jewelry, cash and electrical goods being stolen from their homes (Jackson et al, [43]).

\section{Effect on Family Relationships}

The erratic and demanding behaviour of the substance user forces family members to change their conventional family roles (Copello et al, [66]). This can be undesirable, for example children having excessive responsibility, or grandparents becoming the parents of grandchildren (Mannelli, [42]).

Mothers in Wegner's [53] research describe how they take on the role of 'peace keeper' and engage in 'enabling behaviour', making it easier for the user to carry on using drugs/alcohol by shielding them from the negative consequences. Examples are buying drugs for them, financing everyday activities, taking care of their physical needs, and trying to keep normal family life going by clearing up after them. An indirect consequence is adapting their own behaviour, routine and life around the user's chaotic lifestyle, such as hiding money in their underwear or locking rooms (Wegner et al, [53]). Mannelli [42] describes this over-concern for the other person as codependent, because the needs and wants of the mother are subsumed by the needs of the user.

Wider family relationships are often negatively impacted or neglected. Other children and partners have less of the mothers' time and attention because of their focus on the user, akin to families where there is a disabled child in need of a lot of attention. Some mothers also describe keeping information back from their husbands in order to keep the peace (Wegner et al, [53]).

Marriage relationships are frequently negatively affected because of conflict and disagreement over how to react to the substance user (Usher et al., [51]; Orford et al, [2]). Parents are torn between wanting to support the substance user and needing to provide a stable environment for their other children (Jackson et al, [38]). Variations in parenting style, between mothers who confront the issues and fathers who avoid conflict, escalate tensions in the home (Orford et al, [2]; Smith \& Estefan, [27]).

\section{Self-preservation}

Wegner et al [53] found mothers of substance users are not able to achieve meaning and purpose through their mothering because their loving and nurturing is blocked. Their mothering is not providing them with positive self-esteem, or the chance to socialize, and is therefore demoralizing. This diminishes their chances of health and wellbeing.

\subsection{Coping Strategies for Families and Support in Their Own Right}

In the UK the main researchers into the issues for families with substance users have been Velleman in Bath and Orford and Copello's team in Birmingham. Their growing research evidence show families play a positive role in helping the user to initiate and undergo treatment, 
and help maintain their recovery in the longer term (Moriarty et al., [63]; Orford et al., [49], Saatcioglu et al., [64]; Smith \& Estefan, [27]). Currently families are marginalized by Treatment services and commissioners (Orford et al, [49]) and professionals need to find ways of supporting families and find effective interventions to support their role (Usher et al, [51]; Orford et al, [49]). The argument is families of substance users have considerable needs in their own right but Treatment services remain focused on the substance user in isolation (Orford et al, [65]).

\section{Conclusions}

Whilst this research is limited some tentative conclusions have been drawn, and indicate areas for future research. This study contributes to the wider literature because there are so few phenomenological studies exclusively of mothers of substance users, and none I have found in the UK.

Historically research focused on looking for causes of substance use within the family and articulated the blame-culture by finding parental skills at fault. The focus was the family system, and the mother's experiences were overlooked. The emphasis on reasons for substance use leaves no room for the lived experience of 'I did my best for my child but my love was not enough'.

The literature illuminates the socially constructed nature of motherhood and highlights how mothering metanarratives place constraints on a woman's ability to make sense of her experience as a mother, particularly if the experience is not a good one. The culture of blaming mothers is particularly evident in this client group because substance use is seen as a choice, and the cultural assumption in many Treatment services is families are part of the problem.

The research highlighted the sense of moral obligation the metanarratives impose on the participants, affecting their experience, purpose, and identity. They were left struggling to understand who they are in relation to the 'other'; in relation to their adult child whom they 'should' be keeping safe, and in relation to society whom they felt judged them as failures.

The emotional impact, such as loss, powerlessness, trauma and breakdown of relationships are the province of counselling and personal social networks. From a counselling perspective Doka's [23] concept of disenfranchised grief highlighted the importance of validating the emotions of this client group, and exploring their manifestations of guilt arising from the mothering metanarratives. When these clients recognize the legitimacy of their response, the disconnect between their self-concept and experiencing would be restored.

The theme of loss was focused on to the detriment of other impacts on the participants such as powerlessness, emotional manipulation, damage to other family relationships, loss of trust, lies, codependency, social isolation, powerlessness, financial burden, the dual diagnosis of mental health and substance use, enabling behaviour, the effects on a mother's health; the list goes on. Further research is needed to develop an in-depth understanding these effects have on mothers and how the impact on their self-concept could be lessened.

Figure 1 demonstrates the overwhelming impact a substance using adult child has on my participants because of the expectations placed on them from the metanarratives. Figure 1 suggests society's expectations of such mothers actually cause damage by placing impossible expectations on them, whilst not supporting them. As a society we need a transformation of attitudes so the problem of substance use, and other antisocial behaviour, is not framed along sexist gender lines or seen as a reflection of a mother's deficiencies.

When considering how this client group can be better supported Figure 1 points to areas of impact that could be alleviated by governmental policies, for example the provision of better mental health services and rehabs for users would lessen the impacts of responsibility, powerlessness, family dynamics and isolation for families. If Treatment services supported this client group by treating families and users as equally important at every stage of the care package, it would lessen the stigmatization, guilt and shame of families.

Finally, I would argue more research is needed into the experience of mothering in all its permutations, so an understanding of the 'lived experience' will enable professionals and society to have more realistic expectations of mothers generally, and loosen the influence of the mothering metanarratives. Research into how mothers socially construct their sense of self and sense of blame, in a society where mother-blaming is loud and culturally accepted (Smith \& Estefan, [27]), would mean women's needs, desires, and difficulties as mothers can be better supported and understood.

\section{REFERENCES}

[1] Alcohol concern. Statistics on Alcohol. Available from: https://www.alcoholconcern.org.uk/help-and-advice/statisti cs-on-alcohol/. (accessed 4 August 2015).

[2] Orford J. (2005). A four-year follow-up of close family members of Birmingham untreated heavy drinkers. Addiction Research and Theory. 13(2): 155-170

[3] Orford J, Velleman R, Copello A, Templeton L, \& Ibanga A. (2010a). The experiences of affected family members: A summary of two decades of qualitative research. Drugs: education, prevention and policy. 17(S1): 44-62

[4] Phoenix A, Woollett A, \& Lloyd E, (eds). (1991). Motherhood: Meanings, Practices and Ideologies. London. Sage. 
[5] McMahon M. (1995). Engendering Motherhood: Identity and Self-transformation in Women's Lives. New York. The Guilford Press.

[6] Hopper CJ, Mikulich SK \& Crowley TJ. (2000). Heroin use among adolescents in treatment for substance use disorders. Journal of the American Academy of Child and Adolescent Psychiatry. 39(10): 1316-1323

[7] Spooner C, \& Hill W. (2002). Australian Institute of Family Studies 58: $52-57$. Preventing drug misuse by young people: We need to do more than 'just say no'. Addiction. 97(5): $478-483$

[8] Myles J, and Willner P. (1999). Substance misuse and psychiatric co-morbidity in children and adolescents. Current Opinion in Psychiatry. 12(3): 287-290.

[9] Barnes GM. (1990). Impact of the family on adolescent drinking patterns. In Collins RL, Leonard KE, \& Searles LS (eds) Alcohol and the family: Research and clinical perspectives. New York. Guilford Press. 137-162

[10] Needle RH, Glynn TJ, \& Needle MP. (1983). Drug abuse: Adolescent addictions and the family. In Figley CR, \& McCubbin HI (Eds.). Stress and the family: Volume II, Coping with catastrophe. (37-52). New York. Brunner/Mazel.

[11] Jackson D, \& Mannix J. (2003). Then suddenly he went right off the rails: Mothers' stories of adolescent cannabis use. Contemporary Nurse. 14(2): 169-179

[12] Caplan P, \& Hall-McCorquodale I. (1985). The scapegoating of mothers; a call for change. American Journal of Orthopsychiatry. 55: 610-613

[13] Toumbourou, J., \& Bamberg, J. (2008). Family recovery from youth substance use related problems: A pilot study of the BEST plus program. Substance Use \& Misuse, 43, 1829-1843

[14] Yuen, E., \& Toumbourou, J. (2011). Does family intervention for adolescent substance use impact parental wellbeing? A longitudinal evaluation. The Australian \& New Zealand Journal of Family Therapy, 32, 249-263.

[15] Orford J, Templeton L, Copello A, Velleman R, \& Ibanga A. (2010b). Working with teams and organizations to help them involve family members. Drugs: Education, Prevention and Policy. 17(S1): 154-164

[16] Winnicott DW. (1965). The maturational processes and the facilitating environment: Studies in the theory of emotional development. London. The Hogarth Press Ltd (reprinted 2004)

[17] Swigart J. (1991). The myths of the perfect mother: Parenting without guilt. Chicago, IL. Contemporary Books.

[18] Smith JA, Flowers P, \& Larkin M. (2009). Interpretative Phenomenological Analysis. London, Sage.

[19] Gendlin E. (2003). Focusing, How to gain direct access to your body's knowledge. UK. Rider

[20] Todres L. (2007). Embodied Enquiry, Phenomenological touchstones for research, psychotherapy and spirituality. New York. Palgrave Macmillan.

[21] McLeod J. (2003). Doing Counselling Research. London.
Sage

[22] Zelizer. (1985). In McMahon M. (1995). Engendering Motherhood: Identity and Self-transformation in Women's Lives. New York. The Guilford Press.

[23] Lofland. (1982). In McMahon M. (1995). Engendering Motherhood: Identity and Self-transformation in Women's Lives. New York. The Guilford Press.

[24] Doka K. (1989). Disenfranchised Grief: recognizing hidden sorrow. Canada. Lexington.

[25] Worden JW. (1983). Grief Counselling and Grief Therapy. 2nd Ed. London. Routledge.

[26] Beattie, M. (1992). (2 ${ }^{\text {nd }}$ Ed.) Codependent No More. Minnesota. Hazelden Foundation.

[27] Swidler, A. (1986). "Culture in Action: Symbols and Strategies." American Sociological Review 51:273-86.

[28] Smith J, \& Estefan A. (2014). Families Parenting Adolescents With Substance Abuse - Recovering the Mother's Voice: A Narrative Literature Review. Journal of Family Nursing. 20(4): 415-441

[29] Douglas S, \& Michaels M, (eds). (2004). The Mommy Myth: the idealization of Motherhood and how it has undermined all women. New York. New York Free Press.

[30] Steward I \& Joines V. (2000) ( $2^{\text {nd }}$ Ed.). TA Today: a new introduction to Transactional Analysis. London. Sage.

[31] Gilligan. (1982). In McMahon M. (1995). Engendering Motherhood: Identity and Self-transformation in Women's Lives. New York. The Guilford Press.

[32] Walsh F. (2006). Strengthening family resilience. New York. Guilford Press.

[33] Chodorow, N. \& Contratto, S. (1989) 'The fantasy of the perfect mother', in Feminism and Psychoanalytic Theory, ed. N. Chodorow, Yale University Press, New Haven

[34] Freud S. (1958). The standard edition of the complete works of Sigmund Freud. ( $5^{\text {th }}$ Edition). London. Hogarth Press.

[35] Bowlby J. (1998). A Secure Base; clinical applications of attachment theory. (reprinted 2006). London. Routledge.

[36] Billings J. (1995). Bonding theory - tying mothers in knots? A critical review of the application of a theory to nursing. Journal of Clinical Nursing. 4: 207-211

[37] Parsons T, \& Bale RF. (1955). Family, socialization, and interaction process. Glencoe IL. Free Press.

[38] McGoldrick M, Anderson C, \& Walsh F. (1989). Women in families: A framework for family therapy. New York. W.W. Norton.

[39] Jackson D, \& Mannix J. (2004). Giving voice to the burden of blame: A feminist study of mother's experiences of mother blaming. International Journal of Nursing Practice. 10(4): $150-158$

[40] Wright L M, \& Leahey M. (2013). Nurses and families: $A$ guide to family assessment and intervention (6th ed.) Philadelphia, PA. F.A. Davis.

[41] Chaplin J. (1988). Feminist Counselling in Action. London. Sage. 
[42] Maushart, S. (2006). The mask of motherhood: How mothering changes everything and why we pretend it doesn't. Sydney, Australia: Random House.

[43] Mannelli. (2013). The burden of caring: Drug users \& their families. Indian J Med Res. 137: 636-638

[44] Jackson D, Usher K \& O’Brien L. (2006-7) Fractured families: Parental perspectives of the effects of adolescent drug abuse on family life. Contemporary Nurse. 23: 321330

[45] Anderson, Allan R, Henry, Carolyn S. (1994). Family system characteristics and parental behaviors as predictors of adolescent substance use. Adolescence. 29:114

[46] Barnes GM, Farrell MP, \& Cairns A. (1986). Parental socialization factors and adolescent drinking behaviors. Journal of Marriage and the Family. 48: 27-36

[47] Volk RJ, Edwards DW, Lewis RA, \& Sprenkle DH. (1989). Family systems of adolescent substance abusers. Family Relations. 38: 266-272

[48] McCubbin HI, Thompson AI, Pirner PA, \& McCubbin MA. (1988). Family types and strengths: A life cycle and ecological perspective. Edina, MN: Burgess International Group.

[49] Hopper CJ, Mikulich SK \& Crowley TJ. (2000). Heroin use among adolescents in treatment for substance use disorders. Journal of the American Academy of Child and Adolescent Psychiatry. 39(10): 1316-1323

[50] Orford, J, Templeton L, Patel A, Copello A, \& Velleman R. (2007). The 5-Step family intervention in primary care: strengths and limitations according to family members. Drugs: Education, Prevention and Policy. 14: 29-47

[51] Baldwin, S., Christian, S., Berkeljon, A., Shadish, W., \& Bean, R. (2012). The effects of family therapies for adolescent delinquency and substance abuse: A meta-analysis. Journal of Marriage \& Family Therapy, 38, 281-304

[52] Usher K, Jackson D, \& O’Brien L. (2007). Shattered dreams: Parental experiences of adolescent substance abuse. International Journal of Mental Health Nursing. 16: 422 430

[53] Svenson L, Forster D, Woodhead S, \& Platt G. (1995). Individuals with a chemical dependent family member. Canadian Family Physician. 41: 1488-1493. Retrieved from www.ncbi.nlm.nih.gov/pmc/articles/PMC2146707
[54] Wegner L, Arend T, Bassadien R, Bismath Z, Cros L. (2014). Experiences of mothering drug-dependent youth: influences on occupational performance patterns. South African Journal of Occupational Therapy. 44: 2

[55] Howells E, \& Orford J. (2006). Coping with a problem drinker: a therapeutic intervention for the partners of problem drinkers, in their own right. Journal of Substance Use. 11: 53-71

[56] Suddow. (1967). In Doka K. (ed) Disenfranchised Grief: recognizing hidden sorrow. Canada. Lexington.

[57] Kalish. (1989). In Doka K. (ed) Disenfranchised Grief: recognizing hidden sorrow. Canada. Lexington.

[58] Chapman DL. (1989). In Doka K. (ed) Disenfranchised Grief: recognizing hidden sorrow. Canada. Lexington. 59-64

[59] Laslett AM, Catalano P, Chikritzhs T, Dale C, Doran C, Ferris J, Wilkinson C. (2010). The range and magnitude of alcohol's harm to others. Alcohol Education and Rehabilitation Foundation. Canberra. Australia.

[60] Steinglass P, Bennett L, Wolin SJ, \& Reiss D. (1987). The alcoholic family. New York. Basic Books.

[61] Velleman R, \& Orford J. (1999). Risk and resilience: Adults who were the children of problem drinkers. Reading, UK: Harwood.

[62] Barber JG, \& Crisp BR. (1995). The 'pressures to change' approach to working with the partners of heavy drinkers. Addiction. 90: 269-276.

[63] Pearson G. (2000). Substance abuse and the family. Current Opinion in Psychiatry. 13(3): 305-308.

[64] Moriarty H, Stubbe M, Bradford S, Tapper S, \& Lim BT. (2011). Exploring resilience in families living with addiction. Journal of Primary Health Care, 3: 210-217.

[65] Saatcioglu O, Erim R, \& Cakmak D. (2006). Role of family in alcohol and substance abuse. Psychiatry and Clinical Neurosciences. 60: 125-132.

[66] Orford J, Templeton L, Copello A, Velleman R, Ibanga A, Binnie C. (2009). Increasing the involvement of family members in alcohol and drug treatment services: The results of an action research project in two specialist agencies. Drugs: education, prevention and policy. 16(5): 379-408

[67] Copello A, \& Templeton L. (2012). The Forgotten Carers: support for adult family members affected by a relative's drug problems. (UKDPC, March 2012). 